\title{
Ontology of the Communication Performance Prospects of Building Information Modelling Adoption among Project Teams in Construction Project Delivery
}

\author{
${ }^{*}$ Titus Ebenezer Kwofie ${ }^{1,2}$, Clinton Aigbavboa ${ }^{3}$ and \\ Andrew Baiden-Amissah ${ }^{4}$
}

Published online: 15 July 2020

To cite this article: Titus Ebenezer Kwofie, Clinton Aigbavboa and Andrew Baiden-Amissah (2020). Ontology of the communication performance prospects of Building Information Modelling adoption among project teams in construction project delivery. Journal of Construction in Developing Countries, 25(1): 21-43. https://doi.org/10.21315/jcdc2020.25.1.2.

To link to this article: https://doi.org/10.21315/jcdc2020.25.1.2

\begin{abstract}
The need for improved communication performance among project teams has significantly underlined the increased adoption of many computer-based tools and information communication technology (ICT) in project delivery in the construction industry. Though the literature has espoused the key benefits of Building Information Modelling (BIM), relatively less attention has been paid to the communication performance influence of BIM to profession-specific tasks and wider industry adoption. The primary aim of this study is to assess the communication performance prospects of BIM adoption among project teams in construction project delivery. Using deductive research design, a structured questionnaire survey was conducted on 52 experienced construction industry practitioners in the use of BIM tools in project delivery. The results indicated a significant influence of BIM adoption to accuracy, understanding, timeliness and improvement in the dissemination of shared project related information among project teams. However, contrary to opinion espoused in literature, there was no significant impact on overcoming underloading, overloading and gatekeeping issues in communicated information among the team. The findings provide empirical support into the perceived communication benefits of BIM adoption and thus this knowledge can be an overriding impetus to extensive adoption of BIM tools across all the project life cycle to enhance communication in the construction industry.
\end{abstract}

Keywords: Building Information Modelling, BIM tools, Communication performance, Project team communication, Construction project delivery

\section{INTRODUCTION}

Enhanced communication through prompt, reliable access and sharing of projectrelated information is vaguely reported in literature among the copious benefits of the use of information communication technology (ICT) in project delivery (Eastman et al., 2008; Becerik-Gerber, Gerber and Ku, 2011; Becerik-Gerber and Kensek, 2010). Additional communication-related benefits of the use of ICT is said to include process efficiencies, enhanced coordination and collaboration in construction project delivery (Levitt, 2007; Becerik-Gerber, Gerber and Ku, 2011). However,

\footnotetext{
'Sustainable Human Settlement and Construction Research Centre, Faculty of Engineering and the Built Environment, University of Johannesburg, SOUTH AFRICA

${ }^{2}$ Department of Architecture, Kwame Nkrumah University of Science and Technology (KNUST), Kumasi, GHANA

${ }^{3}$ Faculty of Engineering and the Built Environment, University of Johannesburg, SOUTH AFRICA ${ }^{4}$ Department of Estate Management and Valuation, University of Rwanda, Kigali, RWANDA

"Corresponding author: teeagk@yahoo.co.uk
} 
the construction project delivery process is said to form complex communication networks among team participants and environment coupled with organisational fragmentations and virtuality making communication ineffectiveness a persistent feature (Davies and Harty, 2013; Bryde, Broquetas and Volm, 2013; Chi, Kang and Wang, 2013). The adoption of Building Information Modelling (BIM) in the construction process is perceived to be extensive in the global construction industry but regionally it can be said to be varied. The widest spread use of BIM in the communication context is said to be at the design stage (Sacks et al., 2010; Eastman et al., 2010). This assertion is theoretically underpinned by the fact that BIM tools aid multiple dimensional visualisations that are perceived as potential effective communication benefits. This dimension of the benefit of BIM usage is cursorily asserted to aid understanding, access and timeliness in the sharing of project related information for task function and decisions (Bryde, Broquetas and Volm, 2013; Sacks et al., 2010; Eastman et al., 2010). However, the empirical knowledge and understanding of this perceived communication performance of BIM are lacking any theoretical and practical rigour.

In recent times, most construction projects delivery has adopted one or more project related information sharing technology aimed at enhancing communication performance from a plethora of several available tools (El-Saboni, Aouad and Sabouni, 2009; Ahuja, Yang and Shankar, 2009a; Davies, McMeel and Wilkinson, 2017). However, it has been contended that the mere adoption of any technological tool towards project communication does not automatically stimulate success. Rather the adoption decision of ICT communication tools must consciously be based on the understanding of the communication effectiveness potential of the tool as well as its contextual limitations in its usage (Yang, Ahuja and Shankar, 2007; ElSaboni, Aouad and Sabouni, 2009; Bråthen and Moum, 2016). This is because the knowledge and understanding of the communication potential of ICT tools have a strong significance and catalyses decisions on ICT adoptions to ensure effective communication protocols in project delivery.

A plethora of literature have espoused an increase in BIM adoption and its potential to enhancing communication for many developing countries such as Ghana, Nigeria, South Africa, Rwanda and others (Addy, Adinyira and Ayarkwa, 2018; Abubakar et al., 2014), yet there remains a continuous admission of ineffective communication in construction project delivery still being persistent (see Bernstein and Pittman, 2005; Eastman et al., 2008; Liv et al., 2013). Armah (2015) suggested that BIM adoption in the Ghanaian construction industry (GCI) has the potential to improving communication, information management and protocols in project delivery. However, this assertion is yet to be subjected to and theoretical and practical rigour. Hence, the primary objective of this study is to explore the communication performance potential of BIM as a communication protocol tool in construction project delivery in the $\mathrm{GCl}$. The findings from this study are thus considered very important for engendering effective construction project management protocols and underpin decisions on BIM adoption in project delivery especially in Ghana and other developing countries with similar structural, social, technical and professional characteristics such as Ghana, Nigeria and South Africa. This knowledge will further contribute to the discourse of the communication performance benefits of ICT in construction project communication during project delivery to mitigate the social dilemma induced by project complexities, isolation and fragmentation of the project delivery process (Gu and London, 2010; Leiner et al., 2009; Chi, Kang and Wang, 2013; Eastman et al., 2010). 


\section{LITERATURE REVIEW}

\section{Construction Project Communication and ICT Adoption}

The construction industry and project delivery process are said to be highly data and information-dependent and thus the adversarial, fragmented nature, non-collaborative and widely dispersed nature of participants makes effective communication of project related information almost impossible without the use of ICT. However, literature reflects an incessant report of the available technology not being utilised to their full potential especially in the communication and management of construction-related information (Ahuja, Yang and Shankar, 2009a; 2010; Smith and Tardiff, 2009). Ahuja, Yang and Shankar (2009b) revealed that construction project teams and organisations share information that is needed for managing internal operations, making decisions and policy directions and managing the tasks and actions in the construction project delivery process. In the light of this, ICT is required to integrate, bring agility and induce effective action in the information system and the communication for all of these in an effective manner (Yang, Ahuja and Shankar, 2007; Ahuja, Yang and Shankar, 2009b; 2010; Dawood, Akinsola and Hobbs, 2002; Smith and Tardiff, 2009).

In the construction industry, the adoption of ICT has notably been premised on enhancing integration of the various project phases leading to improvements in performance (Addy, Adinyira and Ayarkwa, 2018; Wong and Zhang, 2013; Wang and Love, 2012; Dawood and Sikka, 2008; Alshawi and Ingirige, 2002). Against this, integration approaches on construction project delivery and in the industry have primarily been pinned on technical and managerial strategies (Yang, Ahuja and Shankar, 2007; El-Saboni, Aouad and Sabouni, 2009; Alshawi, 2007; Alshawi and Faraj, 2002; Dawood and Sikka, 2008; Wong and Zhang, 2013; Craig and Sommerville, 2006). In enhancing technical integration, the focus has been to project information through computer-aided application in workplace technology (Alshawi and Faraj, 2002; Wang and Chong, 2015; Yang, Ahuja and Shankar, 2007). However, in managerial integration, there has been the adoption of the Internet, intranet related computer-supported collaborative work (CSCW) which are sometimes webbased to manage information communication among the project stakeholders and participants to enhanced collaborative work management (Davies, McMeel and Wilkinson, 2017; Dawood and Sikka, 2008; Alshawi and Ingirige, 2002; Goulding, Pour-Rahimian and Wang, 2014). As the growth of adoption of communication technology in the construction industry is increasing, their efficient use is anticipated to be made to effect an impact on traditional processes and develop more efficient collaborative workflows (Davies, McMeel and Wilkinson, 2017; Wang and Love, 2012; Ahuja, Yang and Shankar, 2009a; 2010; Howard and Björk, 2008; Campbell, 2007; Pena-Mora and Tanaka, 2002). On the contrary, it has been contended that the mere adoption of these ICT tools with their related intents does not guarantee results. Rather the clear understanding of the effectiveness of the ICT tools in the sharing of the related information, as well as careful consideration of human-related (e.g culture) issues and their strategic adoption, can potentially engender success (Davies, McMeel and Wilkinson, 2017; Wang and Love, 2012; El-Saboni, Aouad and Sabouni, 2009; Yang, Ahuja and Shankar, 2007; Weippert, Kajewski and Tilley, 2003). 


\section{Traditional Approaches of Construction Communication and BIM Adoption}

From extant literature, it can be noted that the adopted dominant traditional means of construction communication have included the sharing of paper-based contract documents, bill of quantities, 2D drawings, etc. (Mead, 1999; Campbell, 2007; Howard and Björk, 2008; Wang and Love, 2012). A critique of recent happenings and developments in the industry suggests a departure from this traditional paper-based approach to the use of electronic-based means of communication using computer-aided technology (Ahuja, Yang and Shankar, 2009a; El-Saboni, Aouad and Sabouni, 2009; Otter, 2005). Additionally, it can be asserted that this shift from paper-based communication to electronic-based communication has also changed the construction culture with people adopting different ways of communication (Leiner et al., 2009; Rimmington, Dickens and Pasquire, 2015). This has led to the rapid development of various IT tools and means over the last decade through various technological innovations for the creation, transfer and storage of project-related information (Wang and Love, 2012; Wong and Zhang, 2013; Davies, McMeel and Wilkinson, 2017). The adoption of ICT platforms as a communication performance tool in construction communication has evolved from the use of simple Intranet, Internet, groupware in hosting and sharing information and now including the hosting of information from the widely touted BIM (Mead, 1999; El-Saboni, Aouad and Sabouni, 2009; Ahuja, Yang and Shankar, 2010; Adriaanse, Voordijk and Dewulf, 2010).

Leiner et al. (2009) and Rimmington, Dickens and Pasquire (2015) intimated that the use of Internet has revolutionised the computer and communications in an unprecedented way providing a means of information distribution, communication, collaboration and individual interactions via computers devoid of location in various forms. According to Sacks et al. (2010) and Merschbrock and Nordahl-Rolfsen (2016), sharing information in paper format still dominate construction work and thus there are notable shortcomings of using traditional drawings to explore building information in current construction practice. In this regard, shortcomings such as poor portability and improper handling of the drawings, poor display of related information, as well as problems related to browsing and readability are well-acknowledged (Yeh, Tsai and Kang, 2012; van Berlo and Natrop, 2015). According to Hwang, Zhao and $\mathrm{Ng}$ (2013) and Howard and Björk (2008), BIM has been put forward as an ICT tool to respond to the challenge of improper information flow among participating parties, thereby dominating the most adopted means of sharing project related information in construction project delivery. The adoption of BIM is considered a panacea for curtailing most of the significant information sharing challenges which will consequently lead to effective coordination and reduction in reworks as well as scope changes in construction projects through enhanced communication (Hwang, Zhao and Ng, 2013; Howard and Björk, 2008; Bråthen and Moum, 2016). From the extensive studies focusing on the adoption of ICT technologies towards improving communication, coordination and managerial effectiveness in the architectural, engineering and construction (AEC) industry in the last two decades, it can be contended that BIM has received the most rapidly growing attention in the global industry due to its ability to offer a digital representation of the physical and functional characteristics of a building facility as well as a shared knowledge resource for information contributing to a strong and formidable basis of decision making during the project life cycle/phases (Yang, Ahuja and Shankar, 2007; Skibniewski and Zavadskas, 2013; Irizarry, Karan and Jalaei, 2013; Ding et al., 2015; 
Rogers, Heap-Yih and Preece, 2015; Nitithamyong and Skibniewski, 2011; Wong and Zhang, 2013; Bråthen and Moum, 2016).

\section{The BIM and Its Communication Performance Usages}

From existing literature, it can be said that BIM has been defined in various forms (see Jensen and Jóhannesson, 2013; Gu and London, 2010; Arayici et al., 2011; Arayici, Egbu and Coates, 2012; Eadie et al., 2013; Eastman et al., 2008; 2010). However, in the context of information sharing, this study adopts the definition by Eastman et al. (2010) as "a tool, processes and technologies that are facilitated by digital, machinereadable documentation about a building project and facility, its performance, its planning, its construction and later its operation". Campbell (2007) suggested that BIM is a comprehensive information management tool based on the simulation of design and construction rather than merely a three-dimensional (3D) graphic representation of design intent. According to Bråthen and Moum (2016), the most widespread use of BIM today is in the design phase and pre-construction planning. However, in the last decade, the use of BIM in construction project delivery has been explored beyond its traditional design phase and pre-construction planning to embrace on-site activities, project coordination and information update and sharing across other phases of the project life cycle (Merschbrock and NordahlRolfsen, 2016; Wang and Chong, 2015; Sacks et al., 2010; Ahuja, Yang and Shankar, 2010).

Against this background, Sacks et al. (2010) reiterate that BIM is used in sharing and enabling 3D and four-dimensional (4D) visualisation of the building product and this allows for effectively communicating design intent. It is also acknowledged that BIM usage allows for rapid generation of alternative design, building performance prediction, automatically monitoring the integrity of model and reports, providing a communication platform and promoting collaboration between design and construction professions (Sacks et al., 2010; Rogers, Heap-Yih and Preece, 2015; Ding et al., 2015; Campbell, 2007; Ahuja, Yang and Shankar, 2010; Otter, 2005). From this, it can be said that the communication potential of BIM usage is in no doubt essential, and enormous. However, rigorous empirical evidence of its communication performance will seemingly be a very important impetus to legitimising certain decisions, actions and skills in the use and adoption of BIM in construction project communication. Lee and Rojas (2013) and Ahuja, Yang and Shankar (2010) have also revealed that visual representation is an additional attribute of ICT mediated information sharing that enhances the performance of shared information among project teams in construction project delivery by aiding accurate interpretation of the shared data and information.

\section{BIM Adoption in the Ghanaian Context}

The $\mathrm{GCl}$ in the past half a decade has recognised BIM as an integrated tool that has potential to improve process, management and integrated delivery (Addy, Adinyira and Ayarkwa, 2018; Armah, 2015). In the past few years, BIM tools such as Autodesk suite and Bentley suite have become common tools for architectural, structural, cost estimating mechanical and electrical components of projects (Armah, 2015). In respect of asset and facilities management, there are not recognised evidence of BIM usage. It is thus noted that BIM usage in the $\mathrm{GCl}$ is fragmented, unregulated, 
uncoordinated and integrated especially ate the pre-contract stage (Addy, Adinyira and Ayarkwa, 2018; Armah, 2015).

Overall, it can be said that the use of BIM in the $\mathrm{GCl}$ can be described as infantry with no clear policy guidelines and regulations. Despite this obvious observation, it is well acknowledged that BIM adoption has seen a significant surge especially among project teams in the managing project information, sharing and assess from the design phase to closure. However, it is more significant at the construction stage (Addy, Adinyira and Ayarkwa, 2018; Armah, 2015). Armah (2015) and Addy, Adinyira and Ayarkwa (2018) asserted that BIM adoption in the industry in the case of Ghana is motivated by improved performance expectancy. However, the issue of behaviour, social and price value of BIM tools have often affected the decision to adopt on some projects. Generally, there is a high perception that the use of BIM improves information management, integration and access among project teams in the $\mathrm{GCl}$. However, there is yet to be any studies focusing on BIM related communication and information sharing in the $\mathrm{GCl}$ context.

\section{Communication Performance Measurement}

The construction industry is information-intensive and all teams involved in a given construction project need to communicate with one another effectively to satisfy the project requirements. Also, a continuous assessment of the performance of project team communication in construction project delivery is considered a precursor to identifying evaluating and legitimising concepts, process, approach, tools and skills that can engender enhanced effective communication (Xie et al., 2010; Liu, 2009; Marshall-Ponting and Aouad, 2005; Dawood, Akinsola and Hobbs, 2002; Xie, 2002; Xie, Thorpe and Baldwin, 2000; Thomas, Tucker and Kelly, 1998). Thomas, Tucker and Kelly (1998) intimated that the development of a means of measuring and evaluating communication performance is a necessary step towards improving project communications. However, varying concepts, approaches and definitions have been given and applied to communication performance. The performance of communication has often been described by how well the aims and functions of communication are met (Liu, 2009; Thomas, Tucker and Kelly, 1998; Mead, 1999; Dawood, Akinsola and Hobbs, 2002; Xie, Thorpe and Baldwin, 2000).

In the context of assessing the performance of communication, some studies attribute information timeliness, accuracy and completeness as predominant criteria for the measurement (see Dainty, Moore and Murray, 2006; Thomas, Tucker and Kelly, 1998; Xie, Thorpe and Baldwin, 2000; Dawood, Akinsola and Hobbs, 2002; Liu, 2009; Xie et al., 2010). Sonnenwald (1996) and Shen (1992) evaluated issues related to construction project related information sharing as ascribed information underload, information overload, timely delivery of information, a clear understanding of the shared information, easy and unobstructed access to information as the tenets of the effectiveness of the communication performance outcome. The Construction Industry Institute (CII) (1997) evaluated communication performance effectiveness on construction projects by using six critical communication variables, namely accuracy, timeliness, procedure, barriers, understanding and completeness of the shared project information. This approach by Cll (1997) has been described as an important and significant milestone in measuring communication performance towards the improvement of project team communication in construction project delivery (Thomas, Tucker and Kelly, 1998; Xie, Thorpe and Baldwin, 2000; Liu, 2009; Xie et al., 2010; Kwofie, Adinyira and Fugar, 2016). This was further expanded to 
consider issues such as gatekeeping and distortions of the information in some studies (Thomas, Tucker and Kelly, 1998; Liu, 2009; Xie et al., 2010). This has extensively been used in assessing communication problems in construction project delivery.

Drawing from several studies on communication performance measurement in the construction project environment, it could be said that, the CII (1997) has the dominant approach to communication performance assessment in construction project delivery. The emergence and acceptance of the Cll (1997) indicator approaches are underpinned by the fact that the model considers the social and behavioural attribute of communication which is a common feature of the global construction project environment. Against this background, the measure of the communication performance in this article has been perceived as the quality of the communication composition and flow among the project team due to the adoption of BIM tools in the project delivery. Hence, the communication performance outcome consequent from the adoption of BIM tools on construction projects can be conceptualised effectiveness of the accuracy, timeliness, understanding, access, completeness and coherency of the shared information.

By drawing on the practical and theoretical perspective of the construction project environment and the traditional construction industry in Ghana, the communication performance indicators (see Cll, 1997) conceptualised and operationalised as indicated in Table 1.

Table 1. Explanation of the Communication Performance Measurement Variables

\begin{tabular}{|c|c|}
\hline Indicators & Explanatory Variables \\
\hline Accuracies & $\begin{array}{l}\text { 1. Receiving non-conflicting information from team participants. } \\
\text { 2. Consistency in communicated information leading to effective } \\
\text { coordination among the project team. } \\
\text { 3. Conciseness in communicated information among the project team. }\end{array}$ \\
\hline Timeliness & Timely delivery of needed communicated information. \\
\hline Distortions & $\begin{array}{l}\text { 1. Coherency in the meaning of communicated information. } \\
\text { 2. Consistency in the content of communicated information. } \\
\text { 3. Enhanced clarity in communicated information resulting in uniform } \\
\text { interpretations. }\end{array}$ \\
\hline Barriers & $\begin{array}{l}\text { 1. Easy access to communicated and shared information from channels. } \\
\text { 2. Efficient dissemination of information among project team in channels. }\end{array}$ \\
\hline Underloading & $\begin{array}{l}\text { Receiving less information than expected from team participants for } \\
\text { tasks. }\end{array}$ \\
\hline Overloading & Receiving more information than necessary for the tasks than expected. \\
\hline Understanding & Understanding communicated information. \\
\hline Gatekeeping & $\begin{array}{l}\text { 1. Withholding of part of the information by the one who controls } \\
\text { communication. } \\
\text { 2. Withholding of whole of the information by the one who controls } \\
\text { communication. }\end{array}$ \\
\hline Procedure & $\begin{array}{l}\text { 1. Efficient disseminating protocols relating information sharing among } \\
\text { teams. } \\
\text { 2. Clearly defined roles and responsibilities among members of the team. }\end{array}$ \\
\hline
\end{tabular}

Sources: Cll (1997), Thomas, Tucker and Kelly (1998), Xie, Thorpe and Baldwin (2000), Xie (2002), Liu (2009), Xie et al. (2010) and Kwofie, Adinyira and Fugar (2016) 


\section{STUDY METHODOLOGY}

Assessing the influence or impact of factors and other attributes on communication performance outcome is said to lie in the objective and deductive research design domain entailing quantitative explanation of the causal relationship, significance testing and directionality among various variables (see Kwofie, Adinyira and Fugar, 2016; Liu, 2009; Xie et al., 2010; Xie, 2002; Dawood, Akinsola and Hobbs, 2002; Xie, Thorpe and Baldwin, 2000; Thomas, Tucker and Kelly, 1998; Sonnenwald, 1996). A quantitative research design using a structured questionnaire was therefore adopted to collect the primary data assessing the contribution of the use of BIM to the communication performance among project teams in construction project delivery. To ensure valid and reliable data to evaluate the contribution of BIM adoption to the communication performance among project teams in construction project delivery, project team participants who are involved in the management and delivery of projects at the construction stage were deemed as the potential source of data required given that they use BIM tools and are thus considered to have an understanding and experience in using BIM to share project related information. The construction project team participants such as project managers, architects, quantity surveyors, construction managers, engineers, clients, main contractors, subcontractors and suppliers are noted to be involved in the construction stage communication; sharing of information as well as using the adopted communication approach and tools (see Kwofie, Adinyira and Fugar, 2016; Xie et al., 2010; Liu, 2009; Uher and Loosemore, 2004; Dawood and Sikka, 2008; Dawood, Akinsola and Hobbs, 2002).

Thus, the project team participants were deemed as suitable with experience in the use of BIM in sharing project related information and were therefore targeted in a questionnaire survey to elicit their experience on the contribution of BIM adoption to communication performance in construction project delivery. The suitability of using a questionnaire in this study was largely due to the objective and deductive requirements in communication performance assessment expressed in previous studies (see Kwofie, Adinyira and Fugar, 2016; Xie et al., 2010; Liu, 2009; Dawood and Sikka, 2008; Xie, 2002; Xie, Thorpe and Baldwin, 2000; Thomas, Tucker and Kelly, 1998; Sonnenwald, 1996). The questionnaire for the data collection was developed using the communication performance indicators adopted in Table 1. The questionnaire was designed to measure the communication performance in the project team participants have been involved in by indicating the frequency of the effectiveness in those communication performance indicators as a result of the BIM tool adopted on the projects at the construction stage. The measurement was done using the conventional five-point Likert scale similar to previous construction communication performance measures (see Kwofie, Adinyira and Fugar, 2016; Xie et al., 2010; Liu, 2009).

In ensuring reliable data to validly evaluate the extent of the potential influence of BIM adoption on communication performance, it was important to draw on the experience of construction professionals who have been involved in BIM adopted projects in the industry. Given the lack of an organised database of BIM base construction projects in the $\mathrm{GCl}$, the adoption of snowball sampling to select construction projects and construction team participants that have used and delivered projects using BIM was most appropriate. The project team participants who have used and delivered project adopting BIM tools on various projects were invited to indicate the extent to which the use of BIM tools influenced the level of 
communication performance in their project communication based on a five-point Likert rating scale interpreted as "Very Significant" = 5, "Significant" = 4, "Moderately Significant" = 3, "Not Significant" = 2 and "Not Very Significant" = 1. The questionnaires were distributed using both electronic forms (58) and administered personally to participants in their located offices (28). A total of 86 questionnaires were distributed with a yield of 52 responses in the survey within four weeks through a snowballing sampling due to lack of data across all the built environment professionals on the use of BIM in the $\mathrm{GCl}$. The questionnaire also assessed the background of the respondents in respect of their professional roles as well as their experience in the use of BIM tools in their communication on construction projects. These attributes according to Hallowell and Gambatese (2009) are important in ensuring the validity and credibility of the responses and thus offer credence to the research findings. The data collection focused on the experiences in the adoption of BIM at the construction stage in construction project delivery. This is partly due to the fact that, practically, the significant use of BIM in integrated and coordinated communication and information management in the construction industry in Ghana is at the construction phase. Although in the other phases such as inception, design and procurement, there is enough evidence of BIM usage, it is fragmented, uncoordinated and unintegrated. Mean scores were used to aggregate the responses given on the variables in respect to the influence of BIM adoption on the communication performance in their project delivery. To aid conformity in the interpretations of the aggregated means with the scale of the assessment of the influence of BIM usage to communication performance, the mean ratings were approximated to the nearest point on the fivepoint assessment scale used.

Gisev, Bell and Chen (2013) emphasised that assessment of the extent of agreement in the responses among a cluster of varying respondents on a given variable in any quantitative assessment is critical to offer credence and confidence in the interpretation of the mean scores on each variable. Against this, a single item inter-rater agreement index (rWG) for significant agreement among the responses were estimated through simulations based on a uniform null distribution using a sample size (i.e. group size) of 52 and a number of response items of five (i.e. the fivepoint Likert scale) based on 95\% confidence interval estimates (after Gisev, Bell and Chen, 2013). The choice of the rWG was mainly due to its traditional and extensive usage in testing significant agreement among the raters/respondents in statistical measures (see Field, 2009; Cohen, Doveh and Nahum-Shani, 2009; Takim, Akintoye and Kelly, 2004; James, Demaree and Wolf, 1984). The process used in the rWG follows after James, Demaree and Wolf (1984), Cohen, Doveh and Nahum-Shani (2009) and Manu et al. (2014). This was through estimation by running simulations based on a uniform null distribution using a sample size (i.e. group size) of 52 and a number of response items of five (i.e. the five-point Likert scale) on $95 \%$ confidence interval.

\section{DATA ANALYSIS, FINDINGS AND DISCUSSIONS}

\section{Profile of the Background of Respondents}

Out of the total 86 questionnaires distributed via electronic mail and administered personally to participants in their located offices, 52 were received at the end of the four weeks representing a $60 \%$ response rate. This is above the minimum 
recommended $20 \%$ to $30 \%$ response rate recommended for the questionnaire survey (Takim, Akintoye and Kelly, 2004). The banded breakdown of the professional roles in project teams and years of experience in BIM usage is presented in Table 2. Assessment of research instrument reliability is useful in offering credence and acceptance of findings, conclusions and generalisations drawn (Field, 2009). In this study, Cronbach's alpha used in assessing the reliability of the research instrument used. This follows similar approaches by Kwofie, Adinyira and Fugar (2017), Ahadzie, Proverbs and Sarkodie-Poku (2014) and Takim, Akintoye and Kelly (2004). The Cronbach's alpha yielded 0.869 which was above the recommended minimum of 0.700 , suggesting that the instrument used was good and more likely to yield reliability results.

Table 2. Profile of the Professional Background and Experience of Respondents

\begin{tabular}{|c|c|}
\hline Professional Role & Frequency \\
\hline Project manager & $8(15 \%)$ \\
\hline Architect & $10(19 \%)$ \\
\hline Quantity surveyor & $16(31 \%)$ \\
\hline Civil/Structural/Mechanical engineer & $4(8 \%)$ \\
\hline Construction managers & $6(11 \%)$ \\
\hline Main contractors & $4(8 \%)$ \\
\hline Subcontractors & $2(4 \%)$ \\
\hline Suppliers & $2(4 \%)$ \\
\hline Total & $52(100 \%)$ \\
\hline Experience in the Use of BIM & Frequency \\
\hline 1 to 5 years & $36(69 \%)$ \\
\hline 6 to 10 years & $14(27 \%)$ \\
\hline 11 to 15 years & $2(4 \%)$ \\
\hline 16 years and above & $0(0 \%)$ \\
\hline Total & $52(100 \%)$ \\
\hline BIM Software Used & Frequency \\
\hline Autodesk Revit Suite & $24(46 \%)$ \\
\hline Bentley Suite packages (structural, cost, electrical, etc.) & $28(54 \%)$ \\
\hline Total & 52 (100\%) \\
\hline
\end{tabular}

\section{Field Data}

From Table 2, it can be deduced that almost all the key professional members that form the project teams are represented (project managers, architects, quantity surveyors, engineers, construction managers, main contractors, subcontractors and suppliers). This result indicates that the notable professionals in the project team are adequately represented and thus the results are likely to reflect balanced opinions 
and experiences in the use of BIM in construction project delivery. Additionally, the experience of the respondents as presented in Table 2 further suggests that about $69 \%$ of the respondents had a maximum of five years of experience whereas about $31 \%$ have had over five years of experience in the use of BIM in construction project delivery in the $\mathrm{GCl}$. The mean working experience of the respondents in the use of BIM was estimated to be approximately two years. With this, it could be suggested that the respondents are deemed to have some form of experience in the use of BIM in construction project delivery and thus, their responses could be interpreted as valid, credible and more likely to reflect the practical reality in BIM communication performance in the GCl. Also, the Revit Suite and Bentley Suite were identified as the main BIM tools being used by the project teams in their project delivery. The Autodesk Revit Suite was mostly used for the designers whereas the structural, costing were done with Bentley setup.

\section{MAIN ANALYSIS AND FINDINGS}

\section{The Extent of Influence of BIM Adoption on Project Team Communication Performance}

The summary of the aggregated mean scores and the level of agreement among the responses using the rWG are presented in Table 3. From Table 3, it could be said that the rWG indices for all the variables had a minimum score of 0.61 and a maximum score of 0.82. According to Gisev, Bell and Chen (2013) and Cohen, Doveh and Eick (2001), a measure of inter-rater agreement is interpreted: < 0 as "Poor Agreement", 0.0 to 0.20 as "Slight Agreement", 0.21 to 0.40 as "Fair Agreement", 0.41 to 0.60 as "Moderate Agreement", 0.61 to 0.80 as "Substantial Agreement" and 0.81 to 1.00 as "Almost Perfect Agreement". From this, it could be said that a minimum score of 0.61 suggests a substantial agreement whereas a maximum score of 0.82 is an indication of almost perfect agreement. Hence, the overall on the results indicate significant consensus amongst the respondents with regards to the interpretation of the assessment on the variables. This is an indication that the aggregated mean ratings of the influence of BIM adoption on communication performance can be considered as being a realistic representation of the respondents' practical judgement based on their experience.

Field (2009) suggested that the standard mean error in any statistical measures is an indication of how representative a sample is likely to be to the population thus enhancing the generalisation that can be accorded the statistical results. In this regard, a large standard mean error is an indication of significant variability between the sample and population means whereas a small value suggests an accurate reflection of the population (Field, 2009; Motulsky, 2005). From Table 3, it can be deduced without any contradiction that, standard mean errors associated with all the mean scores were relatively close to zero (<0.1) (Field, 2009; Motulsky, 2005). This suggests that the sample chosen gives an accurate reflection of the population and thus, the results and findings is a practical reflection of the reality thus giving credence to the results, interpretations and generalisation of the findings in this study.

By rounding off the mean scores in Table 3 to the nearest point (i.e. to conform to the five-point Likert scale), it could be deduced that the overall assessment of BIM adoption show "Very Significant" (5.0) and "Significant" (4.0) influence on communication performance in construction project delivery thus implying that the 
use of BIM tools generally has a potentially significant impact on construction project team communication performance.

The summary of results in Table 3 further shows that the use of BIM tools in construction project delivery induces very significant impact on the accuracy of communication performance in respect of "receiving non-conflicting information from team participants".

Table 3. Extent of Influence of BIM Adoption on Project Team Communication Performance

\begin{tabular}{|c|c|c|c|c|c|}
\hline Indicators & Explanatory Variables & Mean & $\begin{array}{l}\text { Standard } \\
\text { Mean } \\
\text { Error } \\
\text { (SME) }\end{array}$ & rWG & $\begin{array}{l}\text { Overall } \\
\text { Influence }\end{array}$ \\
\hline \multirow[t]{3}{*}{ Accuracies } & $\begin{array}{l}\text { Receiving non- } \\
\text { conflicting information } \\
\text { from team participants }\end{array}$ & 4.52 & 0.070 & 0.78 & $\begin{array}{c}\text { Very } \\
\text { significant }\end{array}$ \\
\hline & $\begin{array}{l}\text { Consistency in } \\
\text { communicated } \\
\text { information leading to } \\
\text { effective coordination } \\
\text { among the project } \\
\text { team }\end{array}$ & 3.75 & 0.093 & 0.67 & Significant \\
\hline & $\begin{array}{l}\text { Conciseness in } \\
\text { communicated } \\
\text { information among } \\
\text { the project team }\end{array}$ & 3.75 & 0.077 & 0.75 & Significant \\
\hline Timeliness & $\begin{array}{l}\text { Timely delivery } \\
\text { of needed } \\
\text { communicated } \\
\text { information }\end{array}$ & 4.17 & 0.094 & 0.69 & Significant \\
\hline \multirow[t]{3}{*}{ Distortions } & $\begin{array}{l}\text { Coherency in } \\
\text { the meaning of } \\
\text { communicated } \\
\text { information }\end{array}$ & 2.23 & 0.089 & 0.61 & $\begin{array}{c}\text { Not } \\
\text { significant }\end{array}$ \\
\hline & $\begin{array}{l}\text { Consistency in } \\
\text { the content of } \\
\text { communicated } \\
\text { information }\end{array}$ & 4.04 & 0.074 & 0.73 & Significant \\
\hline & $\begin{array}{l}\text { Enhanced clarity } \\
\text { in communicated } \\
\text { information resulting in } \\
\text { uniform interpretations }\end{array}$ & 3.75 & 0.062 & 0.71 & Significant \\
\hline Barriers & $\begin{array}{l}\text { Easy access to } \\
\text { communicated and } \\
\text { shared information } \\
\text { from channels }\end{array}$ & 4.37 & 0.073 & 0.70 & Significant \\
\hline
\end{tabular}


Table 3. (continued)

\begin{tabular}{|c|c|c|c|c|c|}
\hline Indicators & Explanatory Variables & Mean & $\begin{array}{l}\text { Standard } \\
\text { Mean } \\
\text { Error } \\
\text { (SME) }\end{array}$ & rWG & $\begin{array}{l}\text { Overall } \\
\text { Influence }\end{array}$ \\
\hline & $\begin{array}{l}\text { Efficient dissemination } \\
\text { of information among } \\
\text { project team in } \\
\text { channels }\end{array}$ & 4.10 & 0.082 & 0.68 & Significant \\
\hline Underloading & $\begin{array}{l}\text { Receiving less } \\
\text { information than } \\
\text { expected from team } \\
\text { participants for tasks }\end{array}$ & 1.28 & 0.074 & 0.73 & $\begin{array}{l}\text { Not very } \\
\text { significant }\end{array}$ \\
\hline Overloading & $\begin{array}{l}\text { Receiving more } \\
\text { information than } \\
\text { necessary for the tasks } \\
\text { than expected }\end{array}$ & 1.19 & 0.089 & 0.62 & $\begin{array}{l}\text { Not very } \\
\text { significant }\end{array}$ \\
\hline Understanding & $\begin{array}{l}\text { Understanding } \\
\text { communicated } \\
\text { information }\end{array}$ & 4.29 & 0.088 & 0.68 & Significant \\
\hline \multirow[t]{2}{*}{ Gatekeeping } & $\begin{array}{l}\text { Withholding of part } \\
\text { of the information by } \\
\text { the one who controls } \\
\text { communication }\end{array}$ & 2.17 & 0.081 & 0.70 & $\begin{array}{c}\text { Not } \\
\text { significant }\end{array}$ \\
\hline & $\begin{array}{l}\text { Withholding of whole } \\
\text { of the information by } \\
\text { the one who controls } \\
\text { communication }\end{array}$ & 2.08 & 0.089 & 0.62 & $\begin{array}{c}\text { Not } \\
\text { significant }\end{array}$ \\
\hline \multirow[t]{2}{*}{ Procedure } & $\begin{array}{l}\text { Efficient disseminating } \\
\text { protocols relating } \\
\text { information sharing } \\
\text { among teams }\end{array}$ & 4.06 & 0.049 & 0.82 & Significant \\
\hline & $\begin{array}{l}\text { Clearly defined roles } \\
\text { and responsibilities } \\
\text { among members of } \\
\text { the team }\end{array}$ & 2.38 & 0.075 & 0.76 & $\begin{array}{c}\text { Not } \\
\text { significant }\end{array}$ \\
\hline
\end{tabular}

Notes: rWG indices are based on a uniform null distribution simulation runs using the conventional $95 \%$ confidence interval for group size of 52 and five response options (five-point Likert scale).

Likewise, the impact on "consistency in communicated information leading to effective coordination among project team", "conciseness in communicated information among the project team", "consistency in the content of communicated information", "enhanced clarity in communicated information resulting in uniform interpretations", "timely delivery of needed communicated information", "easy access to communicated and shared information from channels", "efficient dissemination of information among project team in channels", "understanding communicated information" and "efficient disseminating protocols relating information sharing among teams" were deemed to have a significant influence on the use of BIM in project communication effectiveness. However, it is interesting to 
note that, whilst there is a consensus on the need to overcome the communication challenges related to "coherency in the meaning of communicated information" ensure completeness in construction communication through eliminating underloading and overloading of shared information as well as enhancing "clear defined roles and responsibilities among members of the team" to overcome role conflict, the influence of BIM adoption in the delivery of construction projects was deemed as being very insignificant.

\section{DISCUSSION OF FINDINGS}

\section{Accuracy of BIM Adopted Communication}

The findings seem to suggest that the adoption of BIM tools in project delivery significantly enhances the accuracy in the communication performance among the project team by ensuring conciseness and consistencies in the shared information. Evidence from this study further affirms that the incidence of receiving conflicting information among the project participants can be overcome by the adoption of BIM tools. These findings seem to be consistent with Lee and Rojas (2013) and Ahuja, Yang and Shankar (2010) who revealed ICT mediated information sharing and management enhanced by visual representations of data help streamline communication and improve project efficiency through accurate interpretation and use of the information. However, Liu (2009), Sacks et al. (2010) and Rogers, Heap-Yih and Preece (2015) revealed that management and documentation of project related information as well as the medium for sharing such information often impact on the accuracy which is often inherent from the incidence of various organisations and project participants using different types of software applications in accessing information. It can thus be argued that the feature of BIM tools allowing for access to shared information through the same medium, tools or techniques thus enhance standardised and accurate interpretations over other forms of ICT tools used in construction communication.

\section{Timeliness in BIM Communication}

Prompt and fast access to accurate and reliable information shared among project participant has continuously been deemed as critical to achieving success and performance in project delivery (Otter and Emmitt, 2007; Xie, Thorpe and Baldwin, 2000). Liu (2009) revealed that timeliness in the communication of project related information is indicated by the frequency of delivery as well as updating changes in design, schedule and other key documents for prompt decisions and action. In this regard, it is said that timeliness in communication among construction project teams can be enhanced using computer tools for data processing and information management through ICT. However, Ahuja, Yang and Shankar (2010) and Otter (2005) intimated that not all ICT tools can aid timeliness in construction communication but rather a strategic adoption of ICT that allows all the supply chain members prompt access and update irrespective of location. Here in this study, the findings reveal that contribution of BIM tools to timeliness in the shared project-related information among the project team was significant. The plausible explanation is indicated by Merschbrock and Nordahl-Rolfsen (2016), Wang and 
Chong (2015) and Sacks et al. (2010). BIM tools allow for a quick update to project information that is instantly available to all protocols across all project life cycle/ phases. In the light of this, it can be affirmed that the use of BIM tools in construction communication can significantly contribute to alleviating the untimeliness in communication that has been well acknowledged in the industry (see Thomas, Tucker and Kelly, 1998; Mead, 1999; Xie, Thorpe and Baldwin, 2000).

\section{Overcoming Barriers in Communication When BIM is Used}

Otter (2005) revealed that, exploring the use of new ICT tools in construction communication was highly underpinned by the primary recognition that, ICT tools might solve important barriers in team communication in construction project delivery. The problem of barriers leading to difficulty in access to communicated information or inaccessibility due to poor presentation has remained a notable communication problem in the industry (Xie, Thorpe and Baldwin, 2000; Liu, 2009). Here in this study, the results revealed that the contribution to enhancing "easy access to communicated and shared information from channels" and "efficient dissemination of information among project team in channels" as criteria to accessing barriers to information access was significant. This suggests that the use of BIM tools in construction communication enhances access to the communicated information. This finding seems to be consistent and in agreement with Ahuja, Yang and Shankar (2010), Wang and Love (2012) and Otter (2005) that the web-based properties of most ICT tools in information management and sharing in construction communication greatly improves access to information and thus eliminates the challenges associated with the virtuality of project teams in the global construction industry.

\section{Avoiding Distortions in BIM Mediated Communication}

Consistency, clarity and coherency in shared project information during communication among the project team in construction project delivery is among the critical factors in ensuring right decisions and use of information for tasks and actions (Xie et al., 2010; Liu, 2009; Xie, Thorpe and Baldwin, 2000; Dawood and Sikka, 2008; Dawood, Akinsola and Hobbs, 2002). These attributes of communicated information minimise all forms of distortions that are likely to affect the meaning of the information. According to Liu (2009), in a typical construction project environment, information distortion often occurs through conflicting interpretation, change in meaning and lack of clarity and consistency. The results of the study as presented in Table 3 reveal that the adoption of BIM tools significantly influences the consistency and clarity of communication among the project team whereas, in respect of coherency, the impact was adjudged to be not significant to Merschbrock and Nordahl-Rolfsen (2016), Hwang, Zhao and $\mathrm{Ng}$ (2013) and Nitithamyong and Skibniewski (2011) contended that the 3D and 4D visual presentation of drawings and other specialist aspects of project information in BIM environment account for ensuring clarity, coherency and consistency of information which are benefits that are far and above the notable shortcomings other ICT tools used in construction information management, sharing and communication. However, the results reveal a contrary situation in the case of enhancing coherency in the information in BIM adopted communication among the team. 


\section{Understanding Communicated Information in BIM Environment}

Collective or mutual understanding of communicated project information is another important indicator of effective communication performance in construction project delivery as suggested by Thomas, Tucker and Kelly (1998), Dawood, Akinsola and Hobbs (2002) and Xie et al. (2010). As described by Arayici et al. (2011), Bråthen and Moum (2016) and Wang and Chong (2015), BIM remains the most comprehensive information management tool through enhancing understanding of shared information leading to the accurate and coherent interpretation of shared information thus underlining its widespread usage in the industry today. Indeed, the findings in Table 3 seem to affirm this fact, indicating that BIM adoption significantly contributes to understanding project information communicated. Xie, Thorpe and Baldwin (2000) acknowledged that information misunderstanding remains a notable communication challenge among construction project teams and thus an effective information management system enhanced by ICT could aid in curtailing the incidence in project delivery. This should offer an empirical impetus to further advance the adoption of BIM tools as information management and communication platform to engender improvement in the understanding of shared project information among project teams in construction project delivery.

\section{Enhancing Communication Protocols (Procedure)}

Using the accepted procedure in communication has remained the panacea in overcoming role conflicts and enhancing dissemination of project-related information in communication protocols (Ahuja, Yang and Shankar, 2010; Otter, 2005; Shen, 1992). Ahuja, Yang and Shankar (2010) intimated that the strategic adoption of ICT requires that all the supply chain members follow the accepted methods, defined procedures and the communication protocols in a controlled and coordinated manner. This enhances information control, monitoring and effectiveness of feedback to the rest of the project team throughout the project life cycle through better-defined roles and clear protocols. Additionally, Ahuja, Yang and Shankar (2010) further intimated that the use of using computer tools for effective data processing and information management through ICT can bring about the clear definition of roles on projects and information dissemination as assess to the information is by roles and responsibilities on the projects. However, in this study, the empirical results have given evidence that the use of BIM tools has a significant impact on efficient disseminating protocols relating information sharing among teams whereas in the case of "clearly defined roles and responsibilities among members of the team" the influence is adjudged to be not significant. From this, it can be argued that even though there are enough suggestions that, the use of BIM tools have high prospects of improving relationships in collaborative working and reducing role conflicts through clear definition (see Rimmington, Dickens and Pasquire, 2015; Eadie et al., 2013; Eastman et al., 2008), the evidence from the study seems to suggest otherwise.

\section{Ensuring Completeness and Reducing Gatekeeping Impact in BIM Communication}

Liu (2009) and Thomas, Tucker and Kelly (1998) defined completeness of communication as a situation where the information communicated is not less than 
(underload) or more than (overload) what is expected. Information gatekeeping, on the other hand, refers to the act of withholding information by the person who controls the communication in a medium (gatekeeper) (Xie at al., 2010; Thomas, Tucker and Kelly, 1998; Mead, 1999). Liu (2009) and Xie et al. (2010) accounted that, information underload and overload, as well as deliberate holding back of needed information by the gatekeeper, is a common problem in the Chinese and Hong Kong construction industry. However, the revelation by Mead (1999) that the use of ICT tools such as groupware, Intranet and Internet in construction communication has a high propensity to ameliorating issues of completeness of the information and gatekeeping. Against this background, the emergence of a lack of significant influence on improving the completeness of information communicated and overcoming gatekeeping with the use of BIM tools among the project team is surprising. These results offer a practical understanding of stakeholders thinking of finding solutions to information completeness and gatekeeping issues related to project team communication by relying on ICT tools to rethink.

\section{CONCLUSIONS AND IMPLICATIONS OF FINDINGS}

From existing literature, there is the general perception and assertion that BIM is a communication tool that significantly improves communication performance among project teams in construction delivery (see Ahuja, Yang and Shankar, 2010; Jensen and Jóhannesson, 2013; Gu and London, 2010; Bråthen and Moum, 2016). However, there is a lack of studies giving empirical accentuation to this assertion by ascertaining the taxonomy of communication performance inherent from BIM tools. This article has sought to fill this knowledge gap by examining the profile of the influence BIM adoption could have on the communication performance among the project team in construction project delivery. This study has drawn on the experiences of the project teams in the $\mathrm{GCl}$ in the use of BIM tools and identified their inherent contribution to the communication performance among those project teams. Through this study, some inherent communication performance attributes on BIM adopted communication in construction project environment seem to concur with some noted outcomes in general literature while others could be seen as an eye-opener.

The results in this study show that the adoption of BIM in project team communication and information management induces significant contribution to the accuracy of communication, improves understanding of the shared information and enhances the timeliness of the communicated information among the project team. However, in the case of ensuring completeness of communication, removing gatekeeping challenges and giving clarity to roles, the impact of BIM was seen to be insignificant. The evidence from this study affirms the fact that the adoption of BIM tools in construction project environment has significant potential in improving communication performance among construction project teams. From extant literature, the existence of the acknowledged communication ineffectiveness in construction project environment inherent from the fragmentation of the supply chain, behavioural and cultural complexities as wells as role-related challenges are real and this should allow stakeholders to adopt BIM as an information management systems that can significantly improve the communication performance outcome in project delivery. 
It has become obvious and widely accepted that, in the last decade, the use of BIM in construction project delivery has been explored beyond its traditional design phase and pre-construction planning to embrace on-site activities, project coordination, information update and sharing across other phases of the project life cycle (Merschbrock and Nordahl-Rolfsen, 2016; Wang and Chong, 2015; Sacks et al., 2010; Ahuja, Yang and Shankar, 2010). Hence, the overall communication performance insights given in this study and the high level of agreement in the response should give credence to the findings which should motivate an increase in the use of BIM as well as offering practical and theoretical implications in the construction industry. The findings indicate that the adoption of BIM tools has a significant contribution to communication performance among the project team. Hence, to overcome the numerous communication-related problems of inaccuracies, misunderstanding, untimeliness and barriers to communication in the construction industry (see Liu et al., 2013; Liu, 2009; Xie et al., 2010; Dawood, Akinsola and Hobbs, 2002, Xie et al., 2000), practitioners develop their skills and knowledge in BIM applications to engender its ease of adoption in the industry. The understanding of profession-specific tasks communication performance, generalisation to various project typologies as well as delivery context and behavioural dimensions were not assessed in this study and they are noted as an apparent limitation. Hence, further studies are required to explore these dimensions of the communication performance impact of BIM tools in construction project delivery.

\section{REFERENCES}

Abubakar, M., Ibrahim, Y.M., Kado, D. and Bala, K. (2014). Contractors perception of the factors affecting Building Information Modelling (BIM) adoption in the Nigerian construction industry. In R.R. Issa and I. Flood (eds.), Computing in Civil and Building Engineering: Proceedings of the 2014 International Conference on Computing in Civil and Building Engineering. Reston, VA: American Society of Civil Engineers (ASCE), 167-178. https://doi.org/10.1061/9780784413616.022.

Addy, M., Adinyira, M. and Ayarkwa, J. (2018). Antecedents of building information modelling adoption among quantity surveyors in Ghana: An application of a technology acceptance model. Journal of Engineering, Design and Technology, 16(2): 313-326. https://doi.org/10.1108/JEDT-06-2017-0056.

Adriaanse, A., Voordijk, H. and Dewulf, G. (2010). The use of interorganisational ICT in United States construction projects. Automation in Construction, 19(1): 7383. https://doi.org/10.1016/j.autcon.2009.09.004.

Ahadzie, D., Proverbs, D. and Sarkodie-Poku, I. (2014). Competencies required of Project Managers at the design phase of mass housing building projects. International Journal of Project Management, 32(6): 958-969. https://doi. org/10.1016/j.ijproman.2013.10.015.

Ahuja, V., Yang, J. and Shankar, R. (2010). IT-enhanced communication protocols for building project management. Engineering, Construction and Architectural Management, 17(2): 159-179. https://doi.org/10.1108/09699981011024678.

- (2009a). Benefits of collaborative ICT adoption for building project management. Construction Innovation: Information, Process, Management, 9(3): 323-340. https://doi.org/10.1108/14714170910973529. 
(2009b). Study of ICT adoption for building project management in the Indian construction industry. Automation in Construction, 18(4): 415-423. https://doi.org/10.1016/j.autcon.2008.10.009.

Alshawi, M. (2007). Rethinking IT in Construction and Engineering: Organisational Readiness. Abingdon, OX: Taylor and Francis. https://doi. org/10.4324/9780203961933.

Alshawi, M. and Faraj, I. (2002). Integrated construction environments: Technology and implementation. Construction Innovation, 2(1): 33-51. https://doi.org/10.1108/14714170210814676.

Alshawi, M. and Ingirige, B. (2002). Web-Enabled Project Management. Salford, UK: School of Construction and Project Management, University of Salford. https://doi.org/10.1016/S0926-5805(03)00003-7.

Arayici, Y., Coates, P., Koskela, L., Kagioglou, M., Usher, C. and O'Reilly, K. (2011). BIM adoption and implementation for architectural practices. Structural Survey, 29(1): 7-25. https://doi.org/10.1108/02630801111118377.

Arayici, Y., Egbu, C.O. and Coates, P. (2012). Building Information Modelling (BIM) implementation and remote construction projects: Issues, challenges, and critiques. Journal of Information Technology in Construction, 17: 75-92.

Armah, N.N. (2015). Assessing the benefits and barriers of the use of Building Information Modelling (BIM) in the Ghanaian building construction industry. MSc diss., Kwame Nkrumah University of Science and Technology.

Becerik-Gerber, B. and Kensek, K. (2010). Building information modeling in architecture, engineering, and construction: Emerging research directions and trends. Journal of Professional Issues in Engineering Education and Practice, 136(3): 139-147. https://doi.org/10.1061/(ASCE)El.1943-5541.0000023.

Becerik-Gerber, B., Gerber, D.J. and Ku, K. (2011). The pace of technological innovation in architecture, engineering, and construction education: Integrating recent trends into the curricula. Journal of Information Technology in Construction, 16:411-432.

Bernstein, P.G. and Pittman, J.H. (2005). Barriers to the adoption of building information modeling in the building industry. In Autodesk Building Solutions Whitepaper. San Rafael, CA: Autodesk Inc.

Bråthen, K. and Moum, A. (2016). Bridging the gap: Bringing BIM to construction workers. Engineering, Construction and Architectural Management, 23(6): 751-764. https://doi.org/10.1108/ECAM-01-2016-0008.

Bryde, D., Broquetas, M. and Volm, J.M. (2013). The project benefits of Building Information Modelling (BIM). International Journal of Project Management, 31 (7): 971-980. https://doi.org/10.1016/j.ijproman.2012.12.001.

Campbell, D.A. (2007). Building Information Modelling: The Web3D Application for AEC. Perugia, Italy: Association for Computing Machinery Inc. https://doi.org/10.1145/1229390.1229422.

Chi, H.-L., Kang, S.-C. and Wang, X. (2013). Research trends and opportunities of augmented reality applications in architecture, engineering and construction. Automation in Construction, 33(10): 116-122. https://doi.org/10.1016/j.autcon.2012.12.017.

Cohen, A., Doveh, E. and Eick, U. (2001). Statistical properties of the rWG(J) index of agreement. Psychological Methods, 6(3): 297-310. https://doi.org/10.1037/1082-989X.6.3.297. 
Cohen, A., Doveh, E. and Nahum-Shani, I. (2009). Testing agreement for multiitem scales with the indices rWG(J) and ADM(J). Organizational Research Methods, 12(1): 148-164. https://doi.org/10.1177/1094428107300365.

Construction Industry Institute (CII) (1997). An assessment tool for improving project team communications. University of Texas at Austin Research Report. Texas: Cll, 105-111.

Craig, N. and Sommerville, J. (2006) Information management systems on construction projects: case reviews. Records Management Journal, 16(3): 131-148. https://doi.org/10.1108/09565690610713192.

Dainty, A., Moore, D. and Murray, M. (2006). Communication in Constructions: Theory and Practice. Abingdon, OX: Taylor and Francis. https://doi. org/10.4324/9780203358641.

Davies, K., McMeel, D.J. and Wilkinson, S. (2017). Making friends with Frankenstein: Hybrid practice in BIM. Engineering, Construction and Architectural Management, 24(1): 78-93. https://doi.org/10.1108/ECAM-04-2015-0061.

Davies, R. and Harty, C. (2013). Measurement and exploration of individual beliefs about the consequences of building information modelling use. Construction Management and Economics, 31 (11): 1110-1127. https://doi.org/10.1080/01 446193.2013 .848994$.

Dawood, N. and Sikka, S. (2008). Measuring the effectiveness of 4D planning as a valuable communication tool. ITCon, 13/Special issue: Virtual and augmented reality in design and construction): 620-636.

Dawood, N., Akinsola, A. and Hobbs, B. (2002). Development of automated communication of system for managing site information using internet technology. Automation in Construction, 11(3): 552-572. https://doi.org/10.1016/S0926-5805(01)00066-8.

Ding, Z., Zuo, J., WU, J. and Wang, J.Y. (2015). Key factors for the BIM adoption by architects: A China study. Engineering Construction and Architectural Management, 22(6): 732-748. https://doi.org/10.1 108/ECAM-04-2015-0053.

Eadie, R., Odeyinka, H., Browne, M., McKeown, C. and Yohanis, M. (2013). An analysis of the drivers for adopting Building Information Modelling. Journal of Information Technology in Construction, 18: 338-352.

Eastman, C., Teicholz, P., Sacks, R. and Liston, K. (2008). BIM Handbook: A Guide to Building Information Modeling for Owners, Managers, Designers, Engineers and Contractors. 1st Ed. New York: Wiley. https://doi.org/10.1002/9780470261309.

Eastman, C.M., Jeong, Y.S., Sacks, R. and Kaner, I. (2010). Exchange model and exchange object concepts for implementation of national BIM standards. Journal of Computing in Civil Engineering, 24(1): 25-34. https://doi.org/10.1061/(ASCE)0887-3801 (2010)24:1 (25).

El-Saboni, M., Aouad, G. and Sabouni, A. (2009). Electronic communication systems effects on the success of construction projects in United Arab Emirates. Advanced Engineering Informatics, 23(1): 130-138. https://doi.org/10.1016/j.aei.2008.07.005.

Field, A. (2009). Discovering Statistics Using SPSS for Windows. 3rd Ed. London: Sage Publications.

Gisev, N., Bell J.S. and Chen, T.F. (2013). Interrater agreement and interrater reliability: Key concepts, approaches, and applications. Research in Social and Administrative Pharmacy, 9(3): 330-338. https://doi.org/10.1016/j.sapharm.2012.04.004. 
Goulding, J.S., Pour-Rahimian, F. and Wang, X. (2014). Virtual reality-based cloud BIM platform for integrated AEC projects. Journal of Information Technology in Construction, 19: 308-325.

Gu, N. and London, K. (2010). Understanding and facilitating BIM adoption in the AEC industry. Automation in Construction, 19(8): 988-999. https://doi.org/10.1016/j.autcon.2010.09.002.

Hallowell, M.R. and Gambatese, J.A. (2009). Construction safety risk mitigation. Journal of Construction Engineering and Management, 135(12): 1316-1323. https://doi.org/10.1061/(ASCE)CO.1943-7862.0000107.

Howard, R. and Björk, B.C. (2008). Building Information Modelling: Experts' views on standardisation and industry deployment. Advanced Engineering Informatics, 22(2): 271-280. https://doi.org/10.1016/j.aei.2007.03.001.

Hwang, B.G., Zhao, X. and Ng, S.Y. (2013). Identifying the critical factors affecting schedule performance of public housing projects. Habitat International, 38: 214-221. https://doi.org/10.1016/j.habitatint.2012.06.008.

Irizarry, J., Karan, E.P. and Jalaei, F. (2013). Integrating BIM and GIS to improve the visual monitoring of construction supply chain management. Automation in Construction, 31: 241-254. https://doi.org/10.1016/j.autcon.2012.12.005.

James, L.R., Demaree, R.G. and Wolf, G. (1984). Estimating within-group interrater reliability with and without response bias. Journal of Applied Psychology, 69(1): 85-98. https://doi.org/10.1037/0021-9010.69.1.85.

Jensen, P. and Jóhannesson, E. (2013). Building Information Modelling in Denmark and Iceland. Engineering, Construction and Architectural Management, 20(1): 99-110. https://doi.org/10.1108/09699981311288709.

Kwofie, T.E., Adinyira, E. and Fugar, F. (2017). Theoretical and practical implications for engendering project team communication effectiveness in mass housing project delivery in Ghana. Journal of Engineering, Design and Technology, 15(6): 826-844. https://doi.org/10.1108/JEDT-09-2016-0064.

- (2016). Modelling the effect of housing design unit contract packaging on mass housing project team communication performance. Journal of Construction in Developing Countries, 21 (1): 35-50. https://doi.org/10.21315/ jcdc2016.21.1.3.

Lee, N. and Rojas, M.E. (2013). Visual representations for monitoring project performance: Developing novel prototypes for improved communication. Journal of Construction Engineering and Management, 139(8): 994-1005. https://doi.org/10.1061/(ASCE)CO.1943-7862.0000687.

Leiner, B.M., Cerf, V.G., Clark, D.D., Kahn, R.E., Klein-rock, L., Lynch, D.C., Postel, J., Roberts, L.G. and Wolff, S. (2009). A brief history of the internet. ACM SIGCOMM Computer Communication Review, 39(5): 22-31. https://doi. org/10.1145/1629607.1629613.

Levitt, R. (2007). CEM research for the next 50 years: Maximizing economic, environmental, societal value of the built environment. Journal of Construction Engineering and Management, 133(9): 619-628. https://doi.org/10.1061/ (ASCE)0733-9364(2007)133:9(619).

Liu, J., Wang, H., Ge, Y. and Huang, J. (2013). Application of multisource information fusion technology in the construction of a secure and emergent transportation platform. Proceedings: International Conference on Transportation Information and Safety 2013: Improving Multimodal Transportation Systems; Information, Safety, and Integration. Reston, VA: American Society of Civil Engineers (ASCE), 237-243. 
Liu, Y. (2009). Critical factors for managing project team communication at the construction stage. PhD diss., The Hong Kong Polytechnic University.

Manu, P., Ankrah, N., Proverbs, D. and Suresh, S. (2014). The health and safety impact of construction project features. Engineering, Construction and Architectural Management, 21 (1): 65-93. http://doi.org/10.1 108/ECAM-07-2012-0070.

Marshall-Ponting, A.J. and Aouad, G. (2005). An nD modelling approach to improve communication process for construction. Automation in Construction, 14(3): 311-321. https://doi.org/10.1016/j.autcon.2004.08.018.

Mead, S.T. (1999). Communication effectiveness in intranet based construction projects. PhD diss., Loughborough University.

Merschbrock, C. and Nordahl-Rolfsen, C. (2016). BIM technology acceptance among reinforcement workers: The case of Oslo Airport's Terminal 2. Journal of Information Technology in Construction, 21: 1-12.

Motulsky, H.J. (2005). Prism 4 Statistics Guide: Statistical Analyses for Laboratory and Clinical Researchers. San Diego, CA: GraphPad Software Inc.

Nitithamyong, P. and Skibniewski, M.J. (2011). Success factors for the implementation of web-based construction project management systems: A cross-case analysis. Construction Innovation: Information, Process, Management, 11: 14-42. https://doi.org/10.1108/14714171111104619.

Otter, A. and Emmitt, S. (2007). Exploring effectiveness of team communication Balancing synchronous and asynchronous communication in design teams. Engineering, Construction and Architectural Management, 14(5): 408-419. https://doi.org/10.1108/09699980710780728.

Otter, A.F.H.J. (2005). Design team communication using a project website. PhD diss., Technische Universiteit Eindhoven.

Pena-Mora, F. and Tanaka, S. (2002). Information technology planning framework for Japanese general contractors. Journal of Management in Engineering, 18(3): 138-149. https://doi.org/10.1061/(ASCE)0742-597X(2002)18:3(138).

Rimmington, A., Dickens, G. and Pasquire, C. (2015). Impact of information and communication technology (ICT) on construction projects. Organization, Technology and Management in Construction: An International Journal, 7(3): 1367-1382. https://doi.org/10.5592/otmcj.2015.3.4.

Rogers, J., Heap-Yih, C. and Preece, C. (2015). Adoption of Building Information Modelling technology (BIM): Perspectives from Malaysian engineering consulting services firms. Engineering, Construction and Architectural Management, 22(4): 424-445. https://doi.org/10.1108/ECAM-05-2014-0067.

Sacks, R., Kaner, I., Eastman, C.M. and Jeong, Y.-S. (2010). The rosewood experiment-building information modeling and interoperability for architectural precast facades. Automation in Construction, 19: 419-432. https://doi.org/10.1016/j.autcon.2009.11.012.

Shen, L.Y. (1992). Information Management in Construction Companies. Hong Kong: Department of Building and Surveying, Hong Kong Polytechnic University.

Skibniewski, M.J. and Zavadskas, E.K. (2013). Technology development in construction: A continuum from distant past into the future. Journal of Civil Engineering and Management, 19(1): 136-147. https://doi.org/10.3846/1392 3730.2012.756060.

Smith, D.K and Tardif, M. (2009). Building Information Modeling: A Strategic Implementation Guide for Architects, Engineers, Constructors and Real Estate Asset Managers. New Jersey: John Wiley \& Sons Inc. https://doi.org/10.1002/9780470432846. 
Sonnenwald, D.H. (1996). Communication roles that support collaboration during the design process. Design Studies, 17(3): 277-299. https://doi.org/10.1016/0142694X(96)00002-6.

Takim, R., Akintoye, A. and Kelly, J. (2004). Analysis of performance measurement in the Malaysian construction industry. In S.O. Ogunlana, C. Chareonngam, P. Herabet and B.H.W. Hadikusumo (eds.), Proceeding of Globalization and Construction. Rotterdam, Netherlands: International Council for Building (CIB), 533-546.

Thomas, S.R., Tucker, R.L. and Kelly, W.R. (1998). Critical communication variables. Journal of Construction Management and Engineering, 124(1): 58-68. https:// doi.org/10.1061/(ASCE)0733-9364(1998) 124:1 (58).

Uher, T.E. and Loosemore, M. (2004). Essentials of Construction Management. Sydney: UNSW Press, 408.

van Berlo, L.A.H.M. and Natrop, M. (2015). BIM on the construction site: Providing hidden information on task specific drawings. Journal of Information Technology in Construction, 20(Special Issue): 97-106.

Wang, X. and Chong, H.-C. (2015). SeVng new trends of integrated Building InformaHon Modelling (BIM) for construction industry. Construction Innovation, 15(1): 2-6. https://doi.org/10.1108/Cl-10-2014-0049.

Wang, X. and Love, P.E.D. (2012). BIM+ AR: Onsite information sharing and communication via advanced visualization. Proceedings of the 2012 IEEE 16th International Conference on Computer Supported Cooperative Work in Design. Piscataway, NJ: Institute of Electrical and Electronics Engineers (IEEE), 850-855. https://doi.org/10.1109/CSCWD.2012.6221920.

Weippert, A., Kajewski, S. and Tilley, P. (2003). The implementation of online information technology (ICT) on remote construction projects. Logistics Information Management, 16(5): 327-340. https://doi.org/10.1 108/09576050310499327.

Wong, A.K.D. and Zhang, R. (2013). Implementation of web-based construction project management system in China projects by Hong Kong developers. Construction Innovation, 13(1): 26-49. https://doi. org/10.1108/14714171311296048.

Xie, C., Wu, D., Luo, J. and Hu, X. (2010). A case study of multi-team communications in construction design under supply chain partnering. Supply Chain Management: An International Journal, 15(5): 363-370. https://doi.org/10.1108/13598541011068279.

Xie, X. (2002). Communications in construction design. PhD diss., Loughborough University.

Xie, X., Thorpe, A. and Baldwin, A.N. (2000). A survey of communication issues in construction design. In A. Akintoye (ed.), Proceedings: 16th Annual ARCOM Conference. Reading, UK: Association of Researchers in Construction Management (ARCOM), 771-780.

Yang, J., Ahuja, V. and Shankar, R. (2007). Managing building projects through enchanted communication: An ICT based strategy for small and medium enterprises. Paper presented at the CIB World Building Congress. Cape Town, South Africa, May.

Yeh, K.-C., Tsai, M.-H. and Kang, S.-C. (2012). The iHelmet: An AR-enhanced wearable display for BIM information. In C.J. Anumba and X. Wang (eds.), Mobile and Pervasive Computing in Construction. Oxford: Wiley-Blackwell, 149-168. https://doi.org/10.1002/9781118422281.ch8. 